\title{
Visualisasi dan Diseminasi Kerangka Induk BS2020 Berbasis Web
} Kerangka Induk Kabupaten Sambas Provinsi Kalimantan Barat

\author{
(Visualization and Dissemination of the Master Framework of the 2020 Census Block in Kabupaten \\ Sambas Provinsi Kalimantan Barat)
}

\author{
Sukron Al Amin ${ }^{1 *}$, Waris Marsisno ${ }^{2}$ \\ ${ }^{1,2}$ Politeknik Statistika STIS \\ Jl. Oto Iskandardinata, 64C, Jakarta Timur \\ E-mail: 221710022@stis.ac.id
}

\begin{abstract}
ABSTRAK
Kerangka induk Blok Sensus 2020 (BS2020) merupakan hasil kegiatan pemetaan oleh Badan Pusat Statistik (BPS) pada tahun 2019 yang berisi kumpulan blok sensus dalam suatu wilayah kerja statistik (wilkerstat) dengan atribut muatan, dominan muatan, dan jenis blok sensusnya. Sistem informasi geografis (SIG) yang digunakan oleh BPS saat ini belum dapat menampilkan peta digital sampai ke level unit analisis terkecil yaitu blok sensus dan satuan lingkungan setempat (SLS). Tujuan dari penelitian ini adalah untuk membangun SIG BS2020 berbasis web yang memiliki kemampuan untuk memvisualisasikan dan mendiseminasikan peta digital sampai level Blok Sensus dan SLS. Pembangunan sistem dilakukan dengan pendekatan metode Rapid Application Development (RAD). SIG untuk Visualisasi dan Diseminasi Kerangka Induk BS2020 dengan studi kasus wilayah kerja statistik Kabupaten Sambas, Provinsi Kalimantan Barat telah berhasil dibangun. Hasil pengujian Black Box memperlihatkan bahwa semua skenario telah berjalan sesuai dengan yang diharapkan. Sementara dari penilaian pengguna dengan metode Scale Usability System diperoleh skor 77.95 yang menunjukkan bahwa sistem telah berfungsi dan dapat diterima dengan baik oleh pengguna.
\end{abstract}

Kata kunci: SIG, visualisasi, RAD, BPS

\section{ABSTRACT}

The Master Framework of the 2020 Census Block (BS2020) is the result of mapping activities conducted by the Central Statistics Agency (BPS) in 2019. This master framework contains a collection of census blocks in a statistical working area (wilkerstat) with the attributes of load, dominant load, and type of census block. The geographic information system (GIS) used by BPS currently cannot display digital maps down to the smallest unit of analysis level, namely the census block and local environmental unit (SLS). The purpose of this research is to build a web-based BS2020 GIS that has the ability to visualize and disseminate digital maps up to the Census Block and SLS levels. System development is carried out using the Rapid Application Development (RAD) method. The GIS for Visualization and Dissemination of the BS2020 Master Framework with case study of the statistical work area of Sambas Regency, West Kalimantan Province has been successfully built. The results of the Black Box testing show that all scenarios have run as expected. Meanwhile, from the user assessment using the Scale Usability System method, a score of 77.95 was obtained which indicates that the system has been functioning and can be well received by users.

Keywords: GIS, visualization, RAD, BPS

\section{PENDAHULUAN}

Pada tahun 2019 BPS melakukan pemetaan SLS di seluruh wilayah Indonesia. Kegiatan ini dilakukan untuk menyiapkan wilayah kerja SP2020 dan untuk membentuk Blok Sensus di tahun 2020 (BS2020). Kebutuhan area pencacahan yang operasional, efisien, dan mudah dikelola sampai 10 tahun ke depan menjadi kebutuhan dalam rancangan survei. Penggunaan klaster dalam rancangan sampling bertujuan agar rancangan lebih efisien baik secara biaya, operasional, dan sampling error yang dalam toleransi.

Direktorat Pengembangan Metodologi Sensus dan Survei sebagai pengampu tanggung jawab penyusunan dan pengembangan kerangka induk, baik area maupun unit analisis, memandang perlu adanya kerangka induk area sampling dan unit analisis yang lengkap, akurat, relevan, dan mutakhir. Salah satu cara untuk mengantisipasi adanya perubahan area pencacahan yang sangat dinamis diperlukan penetapan area pencacahan yang statis dengan jumlah muatan yang relatif seragam dan kemudahan pengelolaan keran gka area pencacahan secara berkesinambungan. Oleh karena itu, diperlukan pembentukan klaster yang memiliki wilayah yang tetap selama 10 tahun ke depan dan jumlah muatan yang relatif seragam. Selanjutnya klaster ini disebut sebagai Blok Sensus (BS). 
Dalam menciptakan kerangka induk area sampling dan unit analisis yang lengkap, akurat, relevan, dan mutakhir, kendala yang dihadapi dengan adanya BS2020 yang baru terbentuk adalah belum adanya aplikasi/sistem dalam mendiseminasikan peta kerangka induk BS2020. Subdirektorat Pengembangan Pemetaan Statistik memandang visualisasi peta BS2020 diperlukan guna memudahkan BPS dalam mendapatkan gambaran menyeluruh tentang kerangka induk suatu wilayah. Dengan adanya visualisasi peta BS2020 akan memudahkan BPS dalam melihat karakteristik wilayah baik dilihat dari sebaran secara spasial, kondisi muatan, maupun muatan dominan dari kerangka induk suatu wilayah.

Penelitian ini memberikan sebuah inovasi melalui sistem informasi geografis yang dapat memperlihatkan gambaran visualisasi dan diseminasi peta BS2020 berbasis digital, baik secara spasial maupun sebaran dalam rangka menciptakan kerangka induk yang sesuai dengan kriterianya dan memanfaatkan dokumentasi BS2020 yang pada gilirannya diharapkan dapat dimanfaatkan oleh BPS Pusat dan Daerah.

Berdasarkan latar belakang yang dipaparkan sebelumnya, dapat diidentifikasi bahwa dalam menciptakan kerangka induk yang lengkap, akurat, relevan, dan mutakhir, penulis memberikan sebuah inovasi dengan SIG yang dapat melihat gambaran peta BS2020 berbasis digital baik secara spasial maupun sebaran.

Sistem berbasis web dibangun dengan memanfaatkan data digital yang tersimpan dalam bentuk shapefile (shp), kemudian akan dilakukan import ke database menggunakan PostgreSQL dan PostGIS serta selanjutnya akan diolah dengan menggunakan bahasa pemrograman dan framework Laravel untuk membangun web.

\section{Kerangka Pikir}

Kebutuhan sistem ini diidentifikasi dan dicermati dengan melakukan wawancara, studi pustaka, dan observasi. Wawancara dilakukan dengan subject matter, yaitu salah satu statistisi ahli muda Pengembangan Pemetaan Statistik Direktorat Pengembangan Metodologi Sensus dan Survei BPS RI, terkait diskusi analisis kebutuhan sistem kemudian melakukan pendalaman subjek melalui studi pustaka dalam Buku Pedoman Pembentukan BS2020 BPS RI dan penelitian terkait serta observasi terhadap SIG yang ada.

Pembangunan sistem dilakukan sesuai dengan kebutuhan yang ada sehingga dapat memberikan solusi terhadap permasalahan yang ada. Sistem berupa sebuah SIG berbasis web yang dibangun agar dapat memberikan informasi secara spasial maupun non spasial hingga informasi tersebut bisa dijadikan pengetahuan dalam kegiatan BPS yang memerlukan daftar maupun gambaran umum BS. Pembangunan sistem ini dilakukan dengan menggunakan framework Laravel (bahasa pemrograman PHP 7), database PostgreSQL dan PostGIS, basemap Google Hybrid dan OpenStreetMap untuk peta dasar sistem, serta JavaScript untuk manipulasi, visualisasi, dan pengolahan data pada pemrograman.

Setelah sistem berhasil dibangun, tahapan selanjutnya adalah melakukan pengujian dengan metode SUS dan Black-Box yang dapat diukur untuk dijadikan bahan evaluasi atau untuk penelitian selanjutnya. Pengujian SUS dan Black-Box ditujukan kepada users sistem ini yaitu subject matter dan pegawai BPS daerah maupun pusat. Apabila sistem sudah layak dalam pengujian, maka hasil akhir penelitian ini adalah sebuah SIG berbasis web dalam memvisualisasikan dan mendiseminasikan kerangka induk BS2020.

\section{Tujuan Penelitian}

Tujuan penelitian ini adalah membangun sistem informasi geografis yang memuat visualisasi dan diseminasi peta kerangka induk BS2020 berbasis web yang dapat membantu BPS dalam mendapatkan gambaran umum sebaran BS dengan kriteria sistem sebagai berikut :

- Visualisasi data pada BS2020.

- Query blok sensus dengan kriteria tertentu.

- Output berupa tabel dan visualisasi peta.

- Batasan akses data yang sesuai dengan wilkerstatnya.

\section{Literatur Terkait}

Arif Maulana (STIS, 2016) mengembangkan sebuah aplikasi yang bernama AVIDITIF atau kependekan dari Aplikasi Visualisasi Data Interaktif. Aplikasi ini dibangun dengan tujuan agar user dapat membuat visualisasi berdasarkan jenis-jenisnya yang berlatar belakang library D3.js. Penelitian ini membahas rancangan suatu user management pada sistem sebagai wadah interaksi antar user. Jenis visualisasi data yang digunakan pada aplikasi ini ada lima jenis yaitu population pyramid, scatterplot matrix, boxplot, chord diagram, dan bullet chart. Aplikasi dibangun dengan tujuan visualisasi data dilakukan secara interaktif, namun jika data belum sesuai dengan format yang ditentukan maka user diwajibkan untuk merubah dan melakukan pengolahan pada data agar sesuai dengan format. Topik penelitian yang ada dalam penelitian Visualisasi dan 
Diseminasi Kerangka Induk BS2020 berbasis web memiliki kesamaan topik dengan penelitian mengenai AVIDITIF, yaitu membangun sebuah sistem yang memuat visualisasi data BPS dan digunakan oleh BPS, namun memiliki perbedaan dalam cakupan data yaitu BS2020, fitur-fitur khusus, dan jenis visualisasinya.

Muhammad Rizki (STIS, 2017) melalui judul penelitiannya Perancangan Web Visualisasi Data Badan Pusat Statistik, Rizki berhasil membangun web visualisasi yang digunakan BPS. Data yang digunakan dalam visualisasi ini berasal dari publikasi BPS dengan memberikan kebebasan kepada user untuk memilih data, variabel vertikal, dan jenis visualisasi sesuai dengan yang telah ditentukan. Jenis visualisasi yang digunakan terdiri dari tujuh jenis yaitu column chart, bar chart, line chart, area chart, chord diagram, sequences diagram dan peta indonesia. Penelitian Visualisasi dan Diseminasi Kerangka Induk BS2020 berbasis web memiliki kesamaan topik dengan penelitian terkait yaitu visualisasi data berbasis web namun memiliki perbedaan sumber data. Sumber data yang digunakan dalam penelitian terkait adalah data yang berasal dari berbagai jenis publikasi BPS. Unit area visualisasi dalam penelitian terkait juga dibangun hanya sampai visualisasi peta Indonesia.

Sistem yang dibangun oleh Fawcet January Makay (Polstat-STIS, 2019) dalam penelitian yang berjudul Pembangunan Sistem Numbering Peta Blok Sensus Berbasis Web memiliki cakupan yang sama dengan penelitian Visualisasi dan Diseminasi BS2020 yaitu kerangka induk BS2020. Tujuan sistem ini dibangun untuk memberikan user kesempatan melakukan numbering pada blok sensus yang ada dalam kerangka induk BS2020 sesuai dengan kaidah penomoran yang BPS gunakan. Penelitian yang dilakukan Fawcet memberikan inspirasi bagi penulis dalam menyajikan data BS2020 ke dalam sebuah web. Perbedaan penelitian ini dengan penelitian terkait adalah penelitian terkait hanya membangun sebuah sistem tanpa adanya informasi visualisasi maupun diseminasi BS2020 dalam web.

\section{METODE}

Metode-metode yang digunakan untuk mencapai tujuan dalam penelitian ini terdiri dari metode pengumpulan data, pembangunan sistem, dan pengujian sistem. Ketiga metode tersebut dilakukan secara berurutan yang diawali dengan metode pengumpulan data untuk mengumpulkan informasi dasar dan mendalam mengenai sistem yang akan dibangun, kemudian memilih metode pembangunan sistem yang efektif sesuai dengan kriteria sistem, dan memilih metode pengujian sistem yang dapat mengukur keberhasilan sistem yang telah dibangun.

Metode pengumpulan data yang digunakan adalah wawancara, studi pustaka, dan observasi. Wawancara dilakukan dengan subject matter yaitu salah satu statistisi ahli muda Subdirektorat Pengembangan Pemetaan Statistik Direktorat Pengembangan Metodologi Sensus dan Survei BPS RI yang dilakukan secara daring menggunakan aplikasi WhatsApp dan Zoom. Wawancara sekaligus diskusi dilakukan guna untuk menggali informasi dasar mengenai kriteria sistem dan cara membangun sebuah SIG yang sering dipakai BPS untuk visualisasi. Studi pustaka yang dilakukan peneliti adalah dengan melakukan literatur pada penelitian terkait serta menggunakan Buku Pedoman Pembentukan BS2020 yang dikeluarkan oleh BPS sebagai penegasan konsep dan definisi dalam penelitian. Observasi yang dilakukan peneliti adalah dengan melakukan pengamatan pada sistem yang ada pada penelitian terkait dalam mencermati UI dan UX, coding, bahasa yang digunakan, framework, dan sebagainya.

Dengan informasi dasar yang diperoleh melalui pengumpulan data dan informasi, peneliti menyimpulkan bahwa pembangunan sistem ini termasuk sebuah proyek yang relatif berat dan membutuhkan waktu yang relatif lama sehingga pemilihan metode pembangunan sistem harus tepat agar pembangunan dapat dilakukan secara efektif dan efisien. Berdasarkan hal ini maka peneliti memilih metode Rapid Application Development (RAD) untuk pembangunan sistemnya. Alasan utama penggunaan metode RAD karena beban kerja proyek yang cukup tinggi dengan konstrain waktu yang cukup ketat. Hal ini sejalan dengan Conrad, Misenar, \& Feldman, J. (2012) yang menyatakan bahwa RAD memungkinkan untuk menghasilkan sistem berkualitas tinggi secara cepat melalui prototyping yang iteraktif, keterlibatan aktif pengguna, dan penggunaan berbagai tool untuk pengembangan sistem komputer.

Tahapan dalam metode RAD secara sederhana hanya terdiri dari perencanaan, perancangan, dan penerapan. 


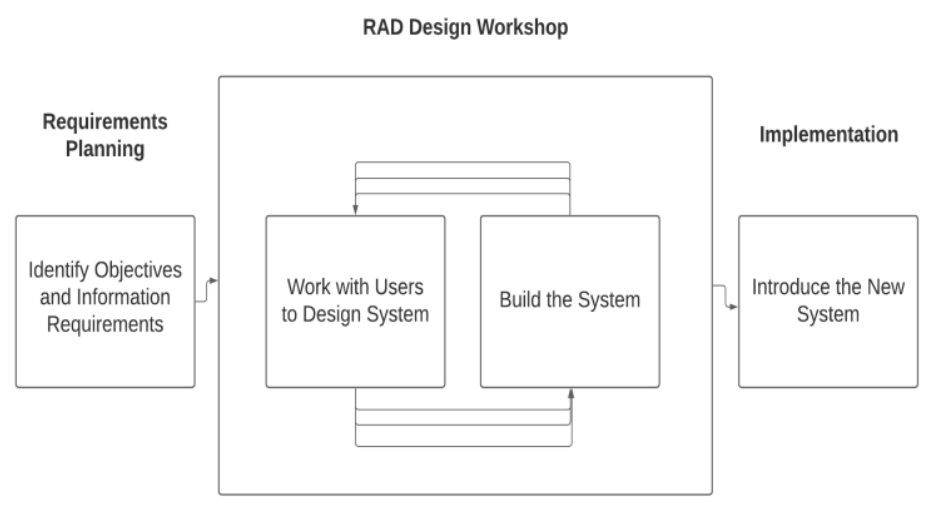

Gambar 1. Tahapan Metode RAD.

Dalam tahapan perencanaan (Requirements Planning) peneliti menggunakan hasil dari pengumpulan data dan informasi kemudian menyusun kebutuhan-kebutuhan sistem yang akan dirancang pada tahap selanjutnya. Perancangan (RAD Design Workshop) dilakukan setelah mendapatkan informasi dasar untuk pembangunan prototipe sistem sesuai dengan kebutuhan dan kemudian akan didiskusikan kembali bersama subject matter melalui WhatsApp atau Zoom. Peneliti memulai perancangan dengan merancang UI dengan membuat mockup menggunakan aplikasi Balsamiq Mockup 3 dan merancang database menggunakan aplikasi DbVisualizer 12.0.6. Untuk menulis kode pemrograman menggunakan aplikasi Visual Studio Code 1.30.2 dengan browser Chrome 91.0.447. Database server yang digunakan peneliti adalah PostgreSQL 11.2 karena mendukung ekstensi PostGIS yang kompatibel dalam membaca data geometry. Pembangunan sistem dilakukan menggunakan bahasa HTML dan PHP serta untuk pengimplementasian polygon dan visualisasi menggunakan JavaScript (JQuery, Leaflet, AJAX, dan DataTable). Peneliti menggunakan framework Laravel agar proses penulisan kode terstruktur dan konsisten serta meminimalisir duplikasi potongan kode yang serupa.

Tabel 1. Daftar JavaScript yang Digunakan Serta Fungsinya.

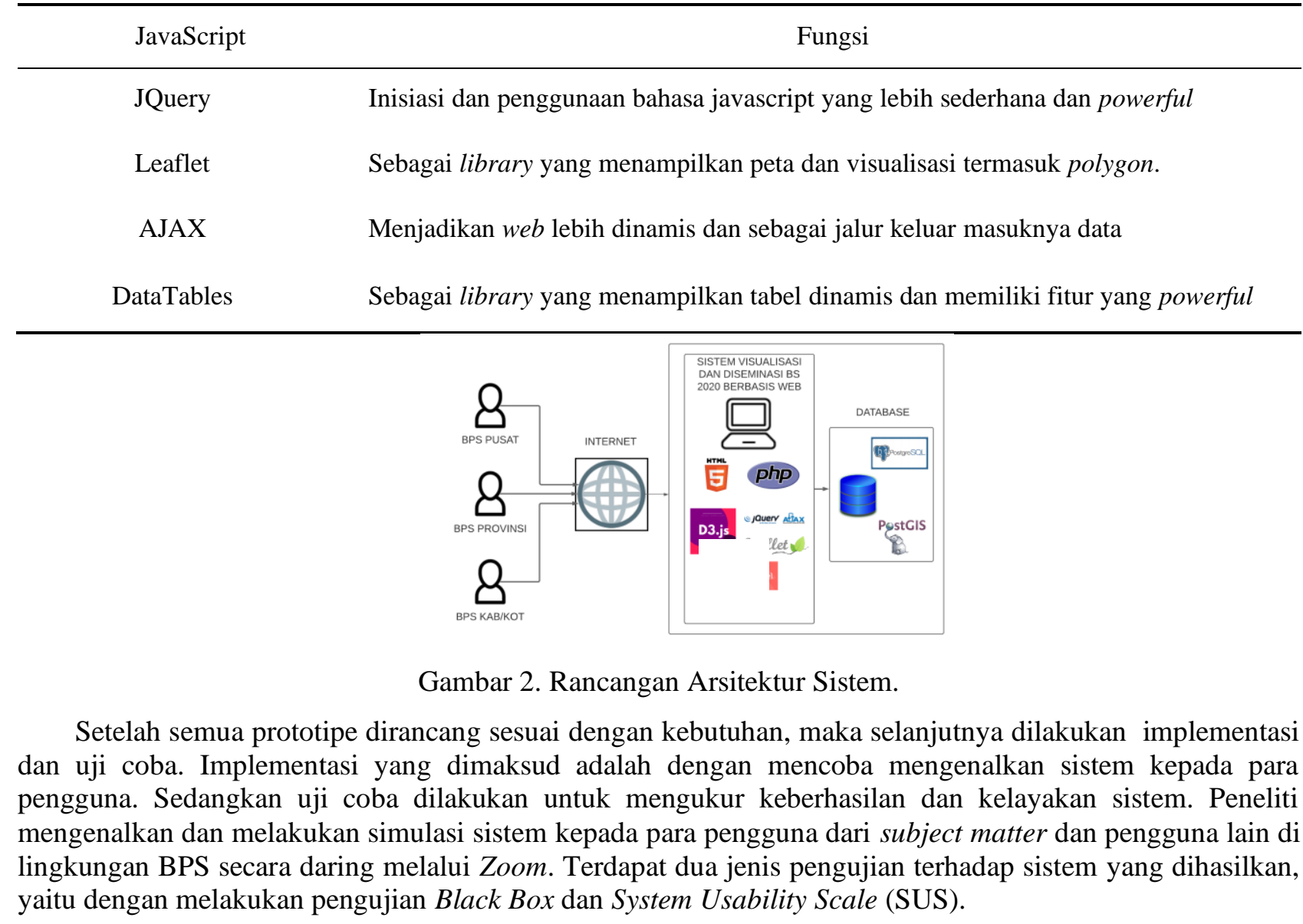


Pengujian Black Box dilakukan oleh dua kolega peneliti yang menjalankan sistem sesuai dengan skenario yang dibuat oleh peneliti dan kemudian memberikan komentar dan pendapatnya tentang hasil uji coba yang dilakukan. Walaupun pengujian black box dapat digunakan untuk berbagai spesifikasi dari sistem yang dihasilkan (Nidhra, 2012) akan tetapi dalam penelitian ini, pengujian Black Box hanya digunakan untuk menguji fungsionalitas dan kemudahan penggunaan dari sistem yang dibuat. Sementara pengujian SUS dengan pengisian kuesioner oleh users sekaligus responden melalui Google Form lebih dimaksudkan untuk mengetahui penerimaan pengguna berdasarkan berbagai aspek dari sistem yang telah dibuat. Penyebaran informasi maupun kuesioner dari peneliti dilakukan melalui subject matter yang menghubungi rekan-rekan satu lingkungan melalui WhatsApp.

\section{Data dan Sumber Data}

Data yang digunakan peneliti disediakan oleh subject matter dari Subdirektorat Pemetaan berupa data BS2020 untuk wilayah kabupaten Sambas, provinsi Kalimantan Barat. Data yang diberikan adalah file GeoJSON polygon wilkerstat seluruh kabupaten di provinsi Kalimantan Barat, dan file GeoJSON polygon wilkerstat serta informasi nonspasial untuk setiap level kecamatan, desa, dan blok sensus yang ada di kabupaten Sambas.

\section{HASIL DAN PEMBAHASAN}

Berdasarkan hasil pengumpulan data dan informasi bahwa eksplorasi data BS2020 belum pernah dilakukan dan sistem yang dapat memberikan kesempatan bagi users untuk melakukan eksplorasi juga belum ada. Peneliti mengidentifikasi permasalahan sebagai berikut :

- Belum ada sistem khusus yang dapat menampung kerangka induk BS2020 yang termutakhir.

- Belum ada penerapan visualisasi dan diseminasi yang dapat dilakukan dengan tujuan mendapatkan informasi berupa spasial maupun non spasial dari BS2020.

- Output visualisasi dan diseminasi BS2020 hingga level BS dalam media cetak seperti peta cetak atau soft file belum ada.

- Belum ada sistem khusus yang dapat memberikan kesempatan bagi BPS untuk melakukan eksplorasi data BS2020 secara visual hingga level BS seperti melakukan query.

Kriteria sistem yang dapat menjadi solusi permasalahan setelah dilakukan analisis kebutuhan adalah sebagai berikut :

- Visualisasi sebaran blok sensus

- Visualisasi sebaran muatan blok sensus

- Query dengan atribut tertentu

- Pemilihan warna, metode klasifikasi (natural breaks, quantile, dan equal), dan jenis tematik peta (choropleth dan size)

- Tabel dan peta digital yang saling terhubung dan interaktif

- Pemilihan basemaps yang menyesuaikan dengan sistem yang sudah ada

- Diharapkan dapat diterapkan penggunaan service request API SSO namun untuk penelitian ini menggunakan tabel duplikasi yang dibedakan dengan server BPS.

Metode visualisasi peta yang digunakan peneliti memperhatikan 3 poin utama, yaitu pemilihan warna, metode klasifikasi (natural breaks, quantile, dan equal), dan jenis tematik peta (choropleth dan size). Dilansir dari situs WebGIS Bappenas, Natural Breaks Interval adalah metode klasifikasi yang menentukan titik pada data dengan melihat pengelompokan dan pola data. Data yang digunakan mempunyai jangkauan dari yang terkecil sampai yang besar. Data kemudian dibagi-bagi dengan batas batas yang ditentukan berdasarkan nilai jangkauan terbesar. Quantile Interval adalah metode klasifikasi dengan menentukan interval berdasarkan jumlah data dibagi jumlah kelas. Equal Interval adalah metode klasifikasi dengan interval didefinisikan sebagai jangkauan dibagi jumlah kelas.

Dalam menyesuaikan kebutuhan user terhadap visualisasi dan diseminasi kerangka induk BS2020, peneliti dan subject matter memandang perlunya output yang tidak hanya dalam bentuk peta, melainkan juga dalam bentuk tabel dan rekapitulasi setiap wilayah peta tematik. Dalam tabel yang terbentuk, setiap barisnya terhubung ke peta saat dilakukan mouse over (muncul highlight) pada tabel maupun peta digital. Fitur peta dan tabel juga dirancang sedemikian rupa agar dapat diunduh dalam bentuk file yang dapat dicetak untuk keperluan kegiatan yang berkaitan dengan pemetaan. Visualisasi dan diseminasi pada peta kerangka induk BS2020 memerlukan peta dasar/basemap sebagai acuan geografis BS2020. Subject matter memberi pilihan basemap OpenStreetMap (OSM), Google Street, dan Google Hybrid. Dalam hal ini peneliti memilih OSM dan Google 
Hybrid sebagai peta dasar sistem dengan alasan bahwa kedua peta dasar tersebut merupakan peta dasar yang sering user dan subject matter gunakan/sukai.

Kebutuhan sistem secara teknis menurut subject matter dalam menyesuaikan penggunaan sistem yang menggunakan fitur login di BPS disesuaikan dengan sistem yang akan dibangun dalam penelitian ini. Login aplikasi dapat dimodifikasi ke request API Single Sign On dengan identitas user diakses melalui service dari sistem yang sudah ada (existing system). Untuk penelitian ini hanya menggunakan duplikasi tabel database user dari existing system yang akan dibedakan koneksinya. User dalam sistem visualisasi dan diseminasi peta hasil kerangka induk BS2020 adalah BPS Pusat, BPS Provinsi, dan BPS Kabupaten/Kota. Yang membedakan role masing - masing user adalah hak akses wilayah dan disesuaikan dengan wilkerstat masing - masing user. Tingkatan peta dalam sistem ini dimulai dari BS, desa, kecamatan, kabupaten, provinsi hingga peta Indonesia.

Implementasi sistem dibangun seefisien mungkin dengan meminimalisir kerumitan logic web dalam penggunaannya. Sistem hanya terdiri dari dua halaman yaitu, login dan dashboard. Berikut perancangan dashboard sistem beserta penjelasannya.

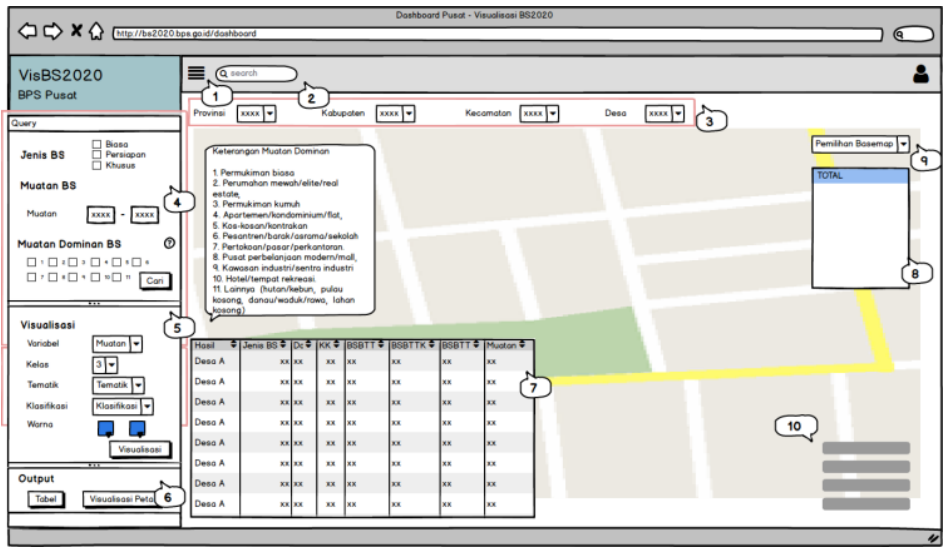

Gambar 3. Rancangan Antarmuka Pengguna.

Tabel 2. Penjelasan Rancangan Antarmuka Pengguna.

\begin{tabular}{cc}
\hline Petunjuk No. & Fungsi \\
\hline 1 & Show/Hide SideBar. \\
2 & Search Prov/Kab/Kec/Desa. \\
3 & Memfilter lokasi tertentu (Dinamis dengan JavaScript / AJAX). \\
4 & Query untuk karakteristik tertentu (Dengan method POST dan tidak boleh kosong). \\
5 & Menampilkan Visualisasi sesuai kebutuhan (Dinamis dengan JavaScript / AJAX) (Dengan \\
& method POST dan tidak boleh kosong). \\
7 & Tabel tabel dan peta visualisasi dan dapat di-export dalam Excel, CSV, PDF dan bisa \\
8 & langsung Print. \\
9 & Info summary dari hasil input wilayah atau query. \\
10 & Pemilihan Basemaps : Google Hybrid dan OpenStreetMap \\
& Legenda visualisasi
\end{tabular}

Dalam mengimplementasi database yang telah dirancang yaitu terdapat 8 tabel utama dan dilakukan pembuatan tabel melalui fitur Model yang ada pada framework Laravel. 8 tabel utama yang saling terhubung yaitu tabel bs, desa, kec, kab, prov, users, roles, dan wilayah_kerja. Setiap tabel memiliki atribut dan hubungan masing-masing yang dapat menggambarkan tabel sehingga karakteristik atau ciri tabel tersebut dapat membedakan tabel yang satu dengan yang lain. Pendefinisian tabel dilakukan setelah melihat struktur data BS2020 yang tersedia sehingga peneliti menyesuaikan kebutuhan atribut-atribut yang hanya digunakan dalam sistem dan melakukan preprocessing tersebut melalui fitur yang pada Laravel. Berikut rancangan fisik database dengan relasi antar tabel. 


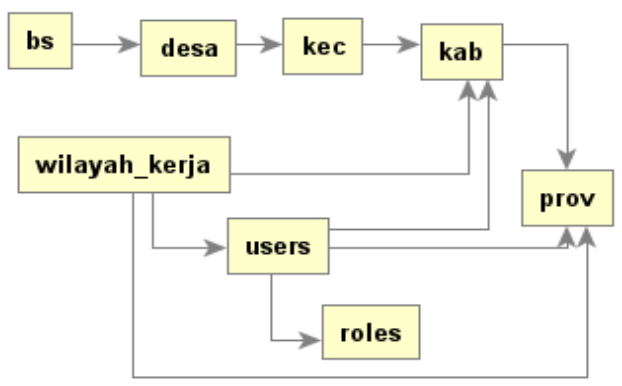

Gambar 4. Rancangan Fisik Database.

Login pengguna menggunakan username dan password yang sama dengan akun BPS community namun untuk penelitian ini menggunakan tabel duplikasi yang diberikan oleh subject matter sebagai referensi penyamaan struktur tabel yang digunakan pada sistem yang serupa. Setelah berhasil login, pengguna akan diarahkan ke dashboard sistem dengan beberapa kemungkinan action yang dapat dilakukan mulai dari filtering wilayah, query, visualisasi, basemaps, dan unduh output berupa tabel dan visualisasi peta. Hal pertama yang harus dilakukan adalah filtering agar dapat menggunakan fitur-fitur lain pada sistem. Dengan kata lain, untuk query, visualisasi, dan unduh output tidak akan dapat dilakukan jika data belum diinput. Jika data sudah tersedia pada dashboard dalam bentuk tabel dan peta digital, maka query, visualisasi, dan unduh output dapat dilakukan. Pengguna dapat melakukan eksplorasi data sesuai dengan kebutuhannya sendiri. Query, visualisasi, dan unduh output dapat dilewatkan jika hanya ingin melakukan analisis dan eksplorasi sederhana saja. Visualisasi dapat dilakukan baik setelah filtering maupun query. Untuk pengunduhan tabel dan visualisasi peta, output yang terunduh adalah kondisi terakhir pada dashboard. Berikut rancangan proses bisnis sistem dalam bentuk flowchart.

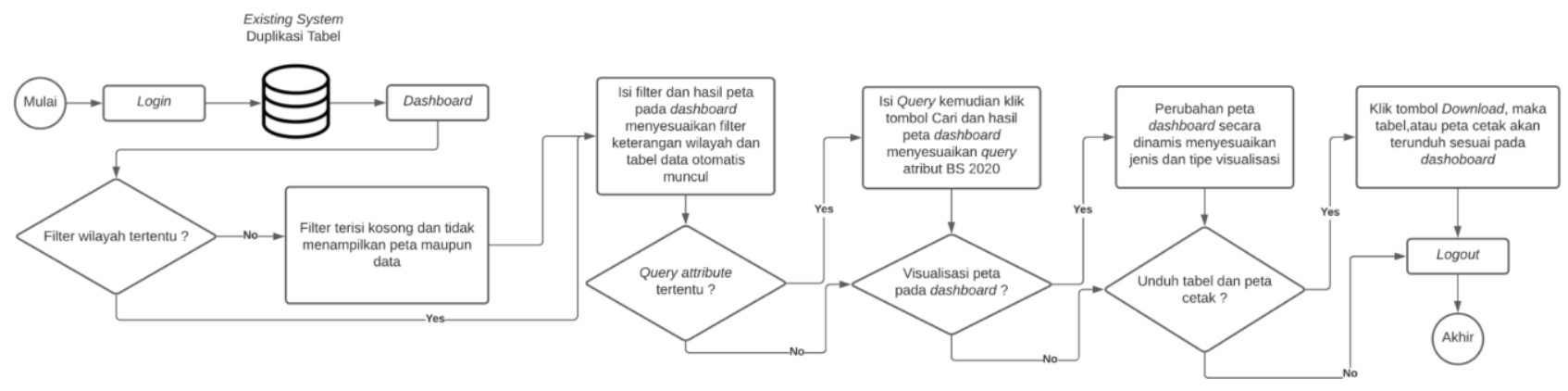

Gambar 5. Rancangan Proses Bisnis.

\section{Implementasi}

Perangkat yang digunakan peneliti adalah sebuah laptop dengan Operating System Windows 10 64-bit, kapasitas RAM 8GB, dengan penyimpanan HDD 1TB, dan graphic Intel HD Graphics 630 128MB. Peneliti memulai implementasi dengan membuat tabel menggunakan fitur Model pada Laravel dan melakukan input data BS2020 dengan mengkonversi format GeoJSON ke .csv kemudian menggunakan fitur Seeder pada Laravel yang bisa memberikan peneliti kebebasan dalam memilih kolom untuk dimasukkan ke dalam database.

Dalam dashboard terdapat 4 fitur utama yaitu filtering, query, visualisasi, dan unduh output dengan memanfaatkan bahasa JavaScript dalam menampilkan UI dan UX yang lebih interaktif. Filtering dilakukan dengan memilih wilkerstat mulai dari level provinsi hingga bs atau minimal dua level dari wilkerstat tersebut. Kode program filtering dibangun sedinamis mungkin dengan hanya menggunakan satu function dalam Controller untuk semua level wilkerstat. Penggunaan function diidentifikasi dari data yang dikirim dari input filtering setiap level melalui AJAX dengan method POST ke Controller kemudian menjalankan function filtering. Return dari function filtering adalah semua wilkerstat di bawal level wilkerstat yang terpilih, tabel, dan peta digital.

Fitur query dibangun dengan memilih tiga kategori dengan ketentuan salah satu harus terisi agar dapat menjalankan fitur tersebut. Fitur ini hanya akan berjalan dengan minimal data yang tersedia pada peta digital adalah data level kabupaten. Fitur query beroperasi dengan mengirim data input melalui AJAX dengan method POST ke Controller kemudian menjalankan function query. Return dari function query adalah semua hasil query dalam level blok sensus, tabel, dan peta digital. 
Fitur visualisasi dibangun dengan memilih lima option select yaitu variabel, kelas, metode klasifikasi, jenis tematik, dan pemilihan warna. Fitur ini hanya akan berjalan dengan syarat harus ada data peta digital baik setelah filtering maupun query. Fitur visualisasi beroperasi dengan mengirim data input hasil pemilihan lima input melalui AJAX dengan method POST ke Controller kemudian menjalankan function visualisasi. Return dari function visualisasi adalah hasil visualisasi sesuai dengan input pemilihan option select, tabel dengan tambahan atribut kelas, peta digital, dan legenda visualisasi.

Fitur unduh output dibangun dengan memilih jenis output yang dipilih yaitu tabel dan/atau peta digital. Fitur ini hanya akan beroperasi jika tabel dan peta digital tersedia pada dashboard. Fitur unduh output menggunakan bahasa JavaScript dengan memanfaatkan fitur yang ada pada datatables.js dan leaflet.js. Tabel dapat diunduh dalam berbagai macam format seperti CSV, Excel, PDF, Copy, atau Print dan peta digital dapat diunduh dalam format PDF atau dapat dicetak langsung melalui browser. Berikut tampilan hasil implementasi sistem.

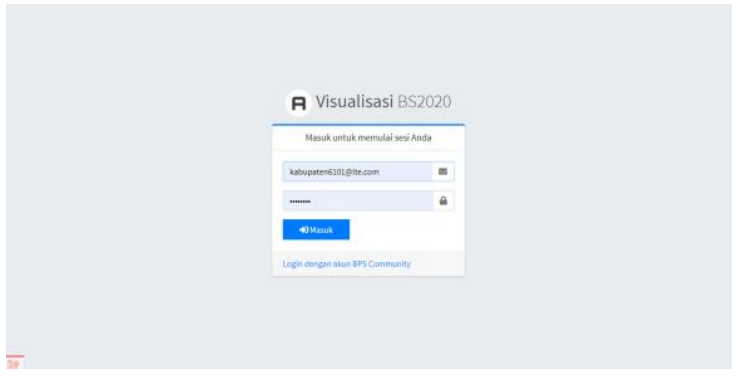

(a)

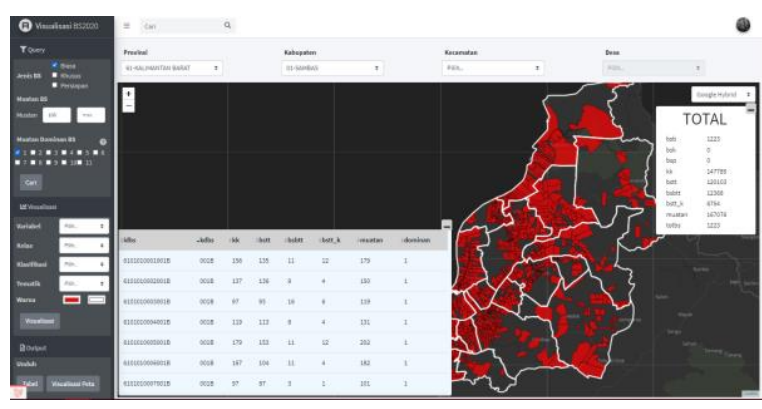

(c)

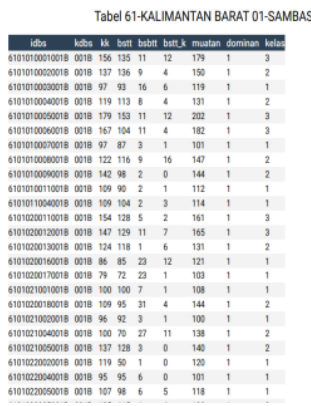

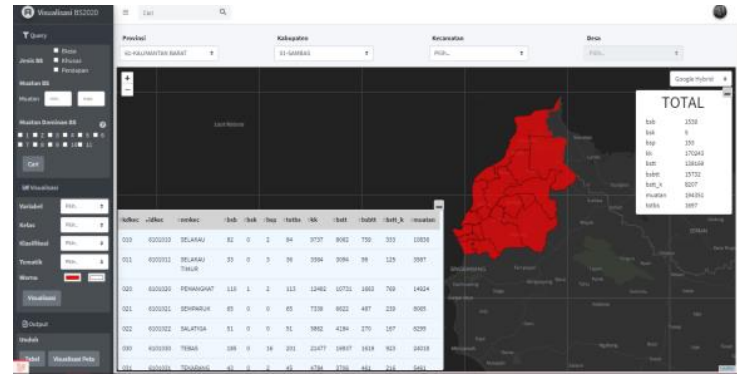

(b)

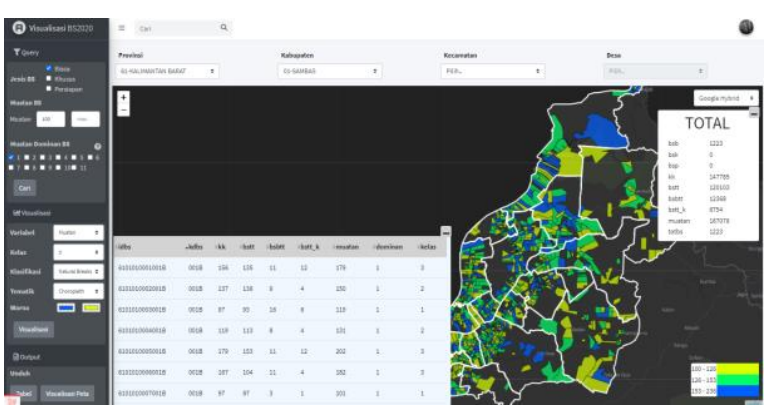

(d)

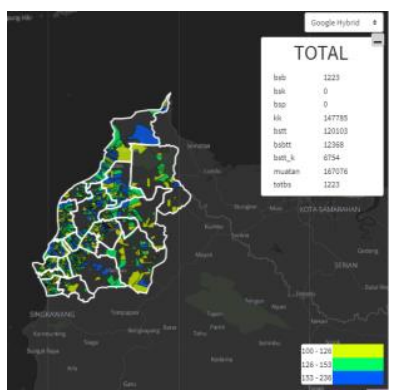

(e)

Gambar 6. Tampilan (a) Login, (b) Filtering, (c) Query, (d) Visualisasi, dan (e) Output berupa Tabel dan Visualisasi Peta

Halaman login menyajikan dua input yang harus diisi user yaitu email dan kata sandi untuk mengidentifikasi role dalam menentukan batasan wilayah yang dapat diakses (Gambar 6a). Setelah login berhasil, tampilan web akan diarahkan menuju halaman yang berisi fitur-fitur (filtering, query, visualisasi, dan menampilkan output) dan peta digital (Gambar 6b, 6c, 6d, dan 6e). Eksplorasi visual data harus diawali dengan filtering dengan memilih wilkerstat terlebih dahulu dan harus terisi minimal sampai level kabupaten. Tampilan peta digital akan diperbaharui setelah memilih wilkerstat ditandai dengan munculnya polygon dan atribut pelengkap informasi lainnya seperti pada Gambar 6b. Untuk fitur query, visualisasi, dan menampilkan output 
dapat dilakukan sesuai dengan keinginan user tanpa adanya keterikatan urutan dan kombinasi dari ketiga fitur tersebut.

\section{Evaluasi dan Pengujian}

Setelah dilakukan pembangunan sistem, peneliti melakukan pengujian dengan Black Box Testing yang terdiri dari total 6 skenario utama dan SUS yang terdiri dari 15 pertanyaan (termasuk uji kelayakan) dengan jawaban berskala 1-5. Responden Black Box Testing sejumlah 2 orang secara acak, respondennya adalah teman kuliah peneliti yang diasumsikan mengerti menjalankan skenario sederhana. Responden SUS terdiri dari 1 subject matter dan 10 rekan subject matter dari lingkungan yang sama. Berikut hasil pengujian yang telah dilakukan.

Tabel 4. Hasil Black Box Testing.

\begin{tabular}{|c|c|c|c|}
\hline No. & Skenario & Hasil yang diharapkan & Keterangan \\
\hline 1 & Melakukan Login & Menampilkan dan mengarahkan ke dashboard sistem & Berhasil \\
\hline 2 & $\begin{array}{l}\text { Memilih wilkerstat } \\
\text { sesuai role }\end{array}$ & Wilkerstat yang tersedia sesuai dengan role user yang melakukan login & Berhasil \\
\hline 3 & $\begin{array}{l}\text { Melihat tabel dan peta } \\
\text { digital yang dinamis } \\
\text { dan interaktif }\end{array}$ & $\begin{array}{l}\text { Tabel dan peta digital yang dinamis dan interaktif serta dapat } \\
\text { menunjukkan highlight }\end{array}$ & Berhasil \\
\hline 4 & Melakukan query & $\begin{array}{l}\text { Query dengan kriteria atribut BS seperti jenis BS, muatan BS, dan } \\
\text { dominan muatan BS serta menunjukkan hasil query dalam bentuk tabel } \\
\text { dan peta digital }\end{array}$ & Berhasil \\
\hline 5 & Melakukan visualisasi & $\begin{array}{l}\text { Visualisasi dilakukan dengan memilih variabel, jumlah kelas, metode } \\
\text { klasifikasi, dan pemilihan warna serta dapat menghasilkan visualisasi } \\
\text { sesuai dengan pilihan user }\end{array}$ & Berhasil \\
\hline 6 & $\begin{array}{l}\text { Mengunduh output } \\
\text { dalam bentuk tabel dan } \\
\text { peta cetak }\end{array}$ & $\begin{array}{l}\text { Tabel dan peta digital dapat diunduh dan disimpan dalam berbagai } \\
\text { format }\end{array}$ & Berhasil \\
\hline
\end{tabular}

Pengujian SUS dengan 15 pertanyaan, 5 di antaranya untuk uji kelayakan (User Acceptance Test). Setiap pertanyaan maksimal bernilai 5 dan minimal 1 , sebagian pertanyaan terpilih dikurangi dengan 1 dan sisanya 5 dikurangi dengan nilai pertanyaan. Total setiap pertanyaan akan dikali 2.5 dan akan mendapatkan skor maksimal 100 dan minimal 0 Skor pengujian SUS adalah 77.95 dan untuk pengujian kelayakan adalah 78.40. Berikut rincian hasil kedua pengujian tersebut.

Tabel 5. Hasil Pengujian SUS

\begin{tabular}{ccc}
\hline Pertanyaan ke- & Total Poin & Nilai \\
\hline 1 & 39 & 88.64 \\
5 & 38 & 86.36 \\
6 & 31 & 70.45 \\
9 & 32 & 72.73 \\
10 & 36 & 81.82 \\
11 & 36 & 81.82 \\
12 & 34 & 77.27 \\
13 & 32 & 72.73 \\
14 & 31 & 70.45 \\
15 & 34 & 72.27 \\
\hline
\end{tabular}


Tabel 6. Hasil Pengujian Kelayakan

\begin{tabular}{cc}
\hline Aspek (Pertanyaan ke-) & Total Poin \\
\hline Kemudahan (2) & 34 \\
Fungsionalitas (3) & 36 \\
Kepuasan (4) & 32 \\
Efisiensi (7,8) & 36 \\
Rata-rata & 34.5 \\
\hline
\end{tabular}

\section{KESIMPULAN}

Hasil dari penelitian ini adalah SIG visualisasi dan diseminasi kerangka induk BS2020 berbasis web telah berhasil dibangun untuk memenuhi kebutuhan dalam mendapatkan gambaran umum mengenai sebaran muatan yang ada pada kerangka induk BS2020 dengan kriteria sebagai berikut :

1. Sistem dibangun sudah sesuai dengan kebutuhan yang telah dianalisis dan dapat melakukan eksplorasi data BS2020 pada semua level wilkerstat.

2. Query pada data BS2020 dapat dilakukan sesuai dengan atribut yang ada.

3. Visualisasi dan diseminasi bekerja sesuai yang diharapkan mulai dari metode klasifikasi hingga jenis tematiknya.

4. Tabel dan peta digital sudah tersedia dalam bentuk halaman web dan keduanya saling interaktif.

5. Sistem hanya memberikan kesempatan memilih wilayah bagi user sesuai dengan role wilkerstatnya masing - masing dan struktur tabel request API SSO sudah sesuai dengan sistem yang ada.

6. Pengujian dengan Black Box dengan 6 skenario memiliki hasil sesuai yang diharapkan dan dilakukan oleh 3 responden.

7. Pengujian dengan SUS dan User Acceptance Test dengan 11 responden memberikan skor akumulatif 77.95 dan 78.40 dengan interpretasi bahwa sistem sudah dapat diterima dengan baik serta sudah berjalan sesuai dengan yang diharapkan.

Pembangunan sistem ini masih memiliki kekurangan dan masih membutuhkan pengembangan dari berbagai aspek seperti performa, UI, UX dll. Sistem dapat dikembangkan menjadi sebuah sistem yang lebih kompleks dan memiliki fitur yang lebih bagus dalam pengoperasiannya. Berikut adalah saran yang dapat diberikan dalam pembangunan sistem.

1. Peningkatan dan pengembangan sistem untuk UI dan UX

2. Peningkatan keamanan data polygon BS2020

3. Penambahan variabel dan pengkombinasiannya dengan sumber data lainnya seperti data Podes, Kependudukan dsb.

4. Pemanfaatan teknologi Web Map Service dan Web Feature Service

5. Penggunaan ArcGIS server yang dapat digunakan untuk pengembangan sistem

\section{DAFTAR PUSTAKA}

Bappenas (2020) Metode Klasifikasi [online]. Available: https://webgissimrenas.bappenas.go.id/simreg/help.html.

BPS, Pedoman Pembentukan BS2020, No. Publikasi 03130.2001, Katalog BPS 1303132, BPS RI, 2020.

Conrad, E., Misenar, S., \& Feldman, J. (2012). Domain 4: Software Development Security. CISSP Study Guide, 169-211. doi:10.1016/b978-1-59749-961-3.00005-4.

F. J. Makay, Pembangunan Sistem Numbering Peta Blok Sensus Berbasis Web. Skripsi PS-STIS, 2019.

IGI Global, Software Design and Development: Concept, Methodologies, Tools, adn Applications. Harshey, Information Science Reference IGI Global, 2013.K. E. Kendall \& J. E. Kendall, System Analysis and Design. Harlow, Pearson, 2002.

K. E. Kendall \& J. E. Kendall, System Analysis and Design. Harlow, Pearson, 2002.

M. A. Maulana, Aviditif : Sistem Aplikasi Visualisasi Data Interaktif. Skripsi PS-STIS, 2016.

M. Rizki, Perancangan Web Visualisasi Data Badan Pusat Statistik. Skripsi PS-STIS, 2017.

Nidhra, S. (2012). Black Box and White Box Testing Techniques - A Literature Review. International Journal of Embedded Systems and Applications, 2(2), 29-50. doi:10.5121/ijesa.2012.2204. 